\title{
FRACTURA Y RESISTENCIA EN ALGUNOS CUENTOS MISIONEROS DE HORACIO QUIROGA
}

\author{
Gina Villamizar \\ Youngstown State University \\ Youngstown, Ohio, Estados Unidos \\ gvillamizar@ysu.edu
}

\begin{abstract}
RESUMEN / ABSTRACT
En los cuentos misioneros de Horacio Quiroga (1878-1937), además de recrear la complicada vida provinciana, se puede observar un interés por exponer la condición de la selva. Esta es hostil, indómita y partícipe de los accidentes absurdos y la muerte trágica de los personajes. Estos cuentos no solo exponen el estado del campo y de sus moradores, sino también el futuro incierto de la sociedad. Esta narrativa pareciera sugerir que el destino de una nación depende exclusivamente del estado de la naturaleza. Para esclarecer esta postura, este trabajo ubica la vida moderna en el centro de esta coyuntura, explorando cómo sus efectos sobre el orden natural del campo ocasionan una fractura irreparable entre la naturaleza y el hombre. Pese al tono pesimista de estos cuentos, este trabajo rescata posturas de resistencia que son consideradas como actos combativos que dejan un precedente de su enfrentamiento a la modernidad.
\end{abstract}

Palabras ClaVe: cuentos misioneros, modernidad, resistencia, sociedad tradicional, muerte.

FRACTURE AND RESISTANCE IN SOME MISSIONARY STORIES BY HoRACIO QUIROGA

In addition to portraying the complicated life of the countryman, Horacio Quiroga's (18781937) Misioneros short stories depict the condition of the countryside. It is, indeed, a hostile, untamed place that plays a significant role in the absurd accidents and tragic deaths of the main characters. These short stories not only indicate the state of the countryside and its inhabitants, but also alert the readers of the unforeseeable future facing this society. In effect, the narrative of Misiones seems to suggest that the fate of this nation depends exclusively on the condition of nature. To clarify this stance, this article explores how the Argentinian modern life disrupted the natural order of the countryside, causing an irreparable rupture between the countryman and his natural surroundings. Despite of Quiroga's pessimistic views, we can find characters with strong critical attitudes which represent combative acts of resistance and confrontation to modernity. 
KEYWORDS: Misioneros, short stories, modernity, resistance, traditional society, death.

El escritor uruguayo Horacio Quiroga (1878-1937) tuvo una intensa y productiva actividad artística durante los primeros años del siglo XX. Los diversos atributos de su obra han permitido ubicarla en distintos momentos de la historiografía literaria latinoamericana, entre los que se destacan su temprana exploración modernista y su experimentación fantástica. Durante la segunda década del siglo XX, el autor comenzó a posicionar a la selva de Misiones, Argentina, en el centro de su producción cuentística. Para muchos, esta tendencia le dio inicio a la etapa telúrica y regionalista en la narrativa del subcontinente ${ }^{1}$. En el caso de los cuentos misioneros de Quiroga, además de la importancia de recrear la complicada vida provinciana, se puede observar un interés por exponer la condición de la selva. Esta es hostil, indómita y participe de los accidentes absurdos y la muerte trágica de los personajes. Con frecuencia, la biografía del autor se ha impuesto a la hora de explicar las circunstancias incoherentes del infortunado deceso de sus personajes campesinos $^{2}$. Más allá del carácter biográfico, los finales de estos cuentos no solo exponen el estado del campo y de sus moradores, sino también el futuro incierto de la sociedad. De tal forma, la narrativa misionera quiroguiana pareciera sugerir que el destino de una nación depende exclusivamente del estado de la naturaleza. Para esclarecer esta postura, este trabajo ubica la vida moderna en el centro de esta coyuntura, explorando cómo sus efectos

1 Críticos como Alberto Zum Felde, Ángel Flores, Emir Rodríguez Monegal, Jaime Alazraki, Elsa K. Gambarini, Noe Jitrick, H.A Murena y Abelardo Castillo, entre otros, han coincido en afirmar que Quiroga es el iniciador de la narrativa criollista-regionalista latinoamericana.

Quiroga debió afrontar tempranamente la muerte de su padre, a causa de un accidente con una escopeta, así como también el suicidio de su padrastro en 1896. A esta tragedia se sumó, después, la muerte de dos de sus hermanos, quienes sufrieron de fiebre tifoidea alrededor de 1901. Más adelante, mató accidentalmente a su amigo Federico Ferrando, mientras maniobraba la pistola que utilizaría su amigo en un duelo. Este hecho hizo que Quiroga estuviera un tiempo en la cárcel y provocó su partida definitiva de su país. El escritor se marchó a Buenos Aires. En Argentina sufrió por el suicidio de su esposa, Ana María Cires, así como por el abandono definitivo de su segunda mujer. Por último, padeció un cáncer de próstata que lo condujo a beber un vaso de cianuro, logrando acabar con su vida en el año de 1937. 
sobre el orden natural del campo ocasionaron una fractura irreparable entre la naturaleza y el hombre. Pese a la complejidad histórica planteada por el autor, es posible rescatar distintas posturas de resistencia que le hacen frente al duro presente recreado.

A principios de siglo XX, las ciudades fueron protagonistas en el desarrollo de los proyectos de modernización en distintas naciones. Desde el ámbito literario, fueron representadas como el escenario idóneo para la fundación de un nuevo tiempo histórico. Esta postura sugirió retratar a la ciudad con apariencias distintas, dotada de novedosas y desconocidas regulaciones. En Buenos Aires, zona influenciada por el espíritu liberal de la época, se impulsó uno de los movimientos migratorios más importantes del subcontinente americano. Estos tiempos de cambios que se vivían al interior de la capital fueron una motivación para que Quiroga encontrara en Misiones no solo un proyecto de vida, sino también un nuevo proyecto literario ${ }^{3}$. Desde este escenario, el autor se propuso llevar a cabo un proceso regenerativo que le permitiera superar el malestar que le había producido el caos de la ciudad. Su refugio en Misiones significó la posibilidad de recuperar un equilibrio con la naturaleza. Sin embargo, el triste final de sus cuentos misioneros insinúa el fracaso de este propósito.

Misiones se convirtió en el ambiente propicio para recriminar la fuerza que había ejercido la ciudad moderna, la cual había logrado contaminar la naturaleza, enfermando a sus residentes locales y provocando su muerte. "A la deriva" (1912), "El regreso de Anaconda" (1925), "El hombre muerto" (1920), y "La cámara oscura" (1920) son tan solo cuatro cuentos misioneros que abordan la conflictiva situación del campesinado y el medio rural. En cada uno de ellos, Quiroga se concentra en hacer "visible[s] los rostros que empezaban a borrarse, las viejas identidades que se disolvían [...] a las víctimas que la sociedad en ascenso iba dejando a su paso" (Morales 57). Más allá de hacer visibles estas imágenes, estos cuentos se empeñan en representar la naturaleza como una entidad ominosa, abominable y hostil. Este gesto repetitivo sirve para evidenciar la dramática alteración del medio.

\footnotetext{
En el año de 1903, Quiroga arribó por primera vez a Misiones, Argentina, para llevar a cabo una investigación y documentación de las ruinas de las misiones jesuíticas de San Ignacio. Su relación con la selva, así como todas las pasiones del escritor, fue intensa. En 1908 se radicó en este lugar. Sin embargo, por razones personales, tuvo que regresar posteriormente a Buenos Aires. Volvió a habitar en Misiones alrededor de 1932, lo que sería su vuelta definitiva.
} 
Es por esto que tiene tanta importancia la participación del espacio como un actante más de la configuración narrativa. Esta disposición le da más fuerza y más efectividad a sus cuentos.

Es sintomático encontrar en estos textos la muerte agónica de jornaleros y de animales. Esta fatalidad sugiere el inicio exitoso de un nuevo orden. Esto significa que la ciudad moderna ha logrado extender sus horizontes, suprimiendo la voluntad del monte e imponiendo las estructuras y las relaciones de poder que allí se efectúan. El campo, como base de la economía, es obligado a seguir un camino sin retorno. Bajo esta perspectiva, la muerte de estos actores del universo misionero es también la muerte simbólica de una parte tradicional de la sociedad. No obstante, pese a la adversidad que encontramos en estos textos, es posible rescatar posturas de resistencia que se relacionan con la lucha continua de sus personajes campesinos protagonistas y su negativa ante la posibilidad de morir. El hecho de encarar la inminente muerte y querer contrarrestarla es ya un acto combativo que deja un precedente de su enfrentamiento a la modernidad.

"A la deriva" (1912) es uno de los primeros cuentos misioneros de Quiroga. En esta narración, un pionero llamado Paulino es atacado por una serpiente mientras laboraba tranquilamente en la selva. El dolor causado por el veneno esparcido por su cuerpo hace que el herido conjeture sobre su propio estado. Para evitar a toda costa su muerte, el herido decide atravesar el río en su canoa y así lograr llegar hasta el pueblo más cercano. Pese al miedo y al insoportable dolor ocasionado por el ataque de la serpiente, afronta con valentía su condición. No obstante, durante este trayecto padece momentos de delirio, lo que hace que pierda el conocimiento y lo conduce finalmente a perder la batalla por la vida. El jornalero muere en su embarcación que todavía flota sobre el río.

El cuento anuncia, desde su inicio, la muerte del tipo de la frontera. Desde el momento que es mordido comienza su lucha por "vencer o ser vencido" (Beauchamp 90). Aquí, el juego con la psicología del personaje es fundamental, ya que es en esta instancia donde el sujeto puede explorar las probabilidades de supervivencia. El herido medita sobre su situación catastrófica y se niega a aceptar lo que parece evidente: "el hombre no se quería morir, y descendiendo hasta la costa subió a su canoa" (110). La acción narrativa transcurre desde el momento que el sujeto es atacado por la serpiente, continúa al llegar a su rancho y termina cuando flota en su canoa por el río. Simultáneamente, la narración nos introduce a una nueva temporalidad que ocurre cuando la víctima se encuentra remando en su embarcación. Desde allí, los delirios del 
herido transitan entre la seriedad de su estado y sus cavilaciones que parecen ser banales. Las reflexiones del moribundo sirven como estrategia discursiva para exponer, por un lado, la perplejidad del accidente y la confusión del sujeto sobre las causas de este evento. Por otro lado, sirven para darle a la muerte un sentido de fatalidad inesperado, tanto para el lector como para el protagonista.

Es sintomático también que el relato dé cuenta de la presencia de nuevos actores en el escenario misionero. Luego del incidente, el campesino recupera memorias de sujetos que son extraños para la vida en la selva. El moribundo hace una referencia explícita a su antiguo jefe: "Acaso viera también a su ex-patrón, míster Dougald, y al recibidor del obraje" (111). La alusión a "míster Dougald" nos informa sobre la participación activa de ciudadanos extranjeros dentro del proyecto nacional. Su aparición sugiere, de hecho, que la modernización no solo ha entrado en vigor sino que también ha logrado penetrar la selva. El sujeto foráneo acredita que ya se han iniciado las propuestas de poblar la nación argentina por inmigrantes europeos y norteamericanos, así como las de colonizar y poblar las zonas más indómitas de la nación, como el desierto (propuestas observadas desde Facundo [1845])4 . De ahí que el tema de la muerte y la representación de la naturaleza como ominosa estén íntimamente relacionados con la presencia de este sujeto extranjero.

En consecuencia, el deceso del jornalero plantea la instauración de un nuevo orden que modifica el régimen de la tenencia de la tierra. En este proceso, el monte misionero cumple un papel primordial. La naturaleza, como fiel acompañante de la vida agraria y como protagonista de la trama narrativa, se distancia de la íntima relación que sostenía con el campesinado y se vuelve en contra de sus pobladores. Esta conducta indica que no solo los residentes de esta localidad han sido afectados por la intromisión de nuevas prácticas

4 Domingo Faustino Sarmiento expone, en su programa político, que la naturaleza salvaje es el obstáculo natural que "mantiene aislados a muchos pueblos y conserva sus peculiaridades primitivas" (13). Asimismo señala que "la vida del campo [...] ha desenvuelto en el gaucho las facultades físicas, sin ningunas de inteligencia. Su carácter moral se resiente de su hábito de triunfar de los obstáculos y del poder de la naturaleza; es fuerte, altivo, enérgico. Sin ninguna instrucción, sin necesidades, es feliz en medio de su pobreza y de sus privaciones" (20). Es por esta razón que plantea como necesaria la masiva inmigración europea en esta zona salvaje: "la pampa, como se pretende, condenada a dar pasto a los animales, sino que en pocos años, aquí como en todo el territorio argentino, ha de ser luego asiento de los pueblos libres, trabajadores y felices" (158). 
urbanas, sino que el espacio ha sido también perturbado en sus funciones. Es por esto que en estos cuentos los tipos de la frontera tienen que morir. Solo así se puede demostrar el éxito del proyecto programado desde la ciudad y su consecuencia nociva para la supervivencia en la selva.

El hecho de que el medio someta a sus pobladores y los doblegue constata que este escenario ha perdido igualmente su batalla. Antes de la expulsión del aldeano, hay ya señales de una naturaleza trastornada y sin identidad: "ya no puede ofrecerles a éstos otro horizonte que no sea el suyo [...] una naturaleza de signos de mal agüero, de fracasos y de desastres" (Morales 56). Esta circunstancia hace que la correspondencia que existía entre Paulino y su universo se desestabilice. Es por esto, también, que la muerte del sujeto no ocurre de manera inmediata. Su agonía indica, paulatinamente, el nuevo estatus del campesinado y de la selva. De esta manera, el desplazamiento del hombre herido en su canoa es, como el mismo título del cuento lo sugiere, un viaje "a la deriva", uno que no tiene retorno, en medio de un río y una selva que también han sido desnaturalizados.

Pese a esta calamidad, en este cuento encontramos posturas de enfrentamiento a la cruda realidad. En efecto, la tensión narrativa aumenta a medida que la víctima se niega a morir. Su capacidad física y sus deseos de superar la adversidad crean un espacio esperanzador de subversión que contraataca la presión del medio. Si bien es cierto que el provinciano muere al final del cuento, esto no se da porque se haya sometido a la inclemencia de la selva y al nuevo pacto que la rige. Aunque su desplazamiento se produce, deja una constancia simbólica de la lucha de una identidad que se niega a desaparecer.

Una posición similar aparece en el cuento "El hombre muerto" (1920). Este se trata de la muerte de un jornalero que permanece anónimo a lo largo del relato; es, simplemente, un hombre. Este personaje tiene un accidente aún más absurdo que el de Paulino de "A la deriva" (1912). Después de terminar su jornada laboral, el hombre decide reposar sobre un bananal que él mismo había plantado, con tal mala suerte que al pasar cerca de un alambre de púas, se resbala y cae directamente sobre su propio machete, que se le incrusta en el estómago y acaba por causar su eventual muerte. La temporalidad narrativa, que no supera los quince minutos, ocurre desde el momento del accidente hasta la muerte del labrador. En un gesto similar al observado con anterioridad, Quiroga abre una nueva temporalidad que nos sumerge en la circulación de imágenes conectadas a la vida familiar del campesino en la selva y a los miedos producidos por la cercanía de la muerte. El hombre, al verse herido mortalmente, se niega a admitir dicha eventualidad: "el hombre 
resiste - ¡es tan imprevisto ese horror!- y piensa: es una pesadilla; jesto es! ¿Qué ha cambiado? Nada. Y mira: ¿no es acaso ese bananal su bananal? ¿No viene todas las mañanas a limpiarlo? ¿Quién lo conoce como él?” (634).

Los cuestionamientos del hombre producen consternación. Es claro que nadie como el jornalero conoce a plenitud los límites y los alcances del monte. Él mismo cultivó y administró las plantaciones. Es por esto que es inexplicable para él la crudeza del momento que vive. Sus preguntas refuerzan su situación catastrófica. Al respecto, el crítico Roberto Paoli ha señalado que esta conducta se relaciona con el caso del "que se va a morir y no puede admitir que su existencia haya llegado al fin en un mundo que sigue su curso imperturbable" (960). Quiroga escenifica aquí una naturaleza que sigue su curso, pero un curso redireccionado hacia otros caminos que informan sobre un nuevo pacto social en su interior. En este acuerdo, la mano de obra del agricultor es desplazada por la inserción de la maquinaria moderna, mientras que el estatus de la naturaleza es alterado por proyectos de industrialización. Es por esto que el machete, como instrumento vital para la supervivencia del hombre en el monte, se convierte, sugerentemente, en el arma que atenta contra su vida. Es realmente absurdo que esta herramienta, pese a haberles brindado sustento económico a él y su familia, termine atacándolo de manera mortal. De hecho, a lo largo del relato se presenta al machete como un personaje más: "el hombre y su machete acababan de limpiar la quinta calle del bananal" (632).

La consternación y la incredulidad que experimenta el hombre son compartidas también por el lector. Esta voluntad forma parte de la estrategia discursiva de Quiroga. Es necesario demostrar, trágicamente, la ruptura entre el hombre y su medio. El machete, como un dispositivo idóneo para la vida en el monte, aparece, en este caso, en desuso. En efecto, la incoherencia del accidente pretende, por un lado, señalar la expulsión de mecanismos correspondientes al escenario rural, pero por otro persigue también demostrar la desintegración de la vida provinciana y de las relaciones que allí solían fomentarse. En el siguiente fragmento, por ejemplo, podemos observar la alteración del medio y de sus agentes, indicando que la naturaleza posee ya un nuevo carácter:

¡Muerto! ¿Pero es posible? ¿No es este uno de los tantos días en que ha salido al amanecer de su casa con el machete en la mano? ¿No está allí mismo, a cuatro metros de él, su caballo, su malacara, oliendo parsimoniosamente el alambre de púa? (634). 
El representar el estado lamentable del medio rural anuncia que el conflicto de la nación se centra en el campo y en la situación del campesinado. En este escenario se produce la desintegración del sujeto nacional, mientras que la naturaleza es obligada a iniciar un nuevo tiempo histórico. Aunque el final del cuento señale la fatalidad de este universo, Quiroga abre una posibilidad de subvertir el inminente destino del hombre. En una conducta similar a la de Paulino, este campesino lucha por no dejarse vencer. Tanto la incredulidad ante el accidente como la recuperación de imágenes y de experiencias conectadas a la naturaleza funcionan como mecanismos de sedición que buscan alzarse contra el dominio y la presión ejercida por la nueva condición del medio.

Tanto en el cuento "A la deriva" (1912) como en "El hombre muerto" (1920), la cercanía de la muerte, así como el miedo y el desconcierto que produce, activan la estructura narrativa de estos relatos. La muerte, sin embargo, depende absolutamente del estado de la naturaleza. Esto quiere decir que este escenario es el que construye, consecutivamente, no solo la tensión que caracteriza estas obras, sino también la debacle de la vida agraria. El monte y sus concomitantes (el machete, el prado, el alambre de púas,), componentes vitales para la supervivencia en este espacio, atacan a los sujetos rurales, constatando que se ha dado una ruptura entre el hombre y su medio. Por un lado, los sujetos son sometidos por la fuerza de una naturaleza engañosa y suplantados por la jerarquía de las máquinas. Por otro, la naturaleza es violentada en su interior y obligada a iniciar un nuevo proceso histórico en el que las antiguas identidades deben desaparecer. De aquí la voluntad de Quiroga de presentar al medio como un personaje activo de la trama narrativa de sus cuentos y así darle la solidez necesaria a su efecto dramático.

El cuento "El regreso de Anaconda" (1925) sigue una línea similar a los cuentos analizados con anterioridad. Éste es quizás uno de los relatos que más ahonda en la problemática condición de la naturaleza, así como uno en el que podemos observar una resistencia más explícita y contundente frente a los efectos del proyecto modernizador en esta zona de la frontera misionera. En "El regreso de Anaconda" (1925), la comunidad de animales de la selva, liderada, justamente, por una anaconda, se subleva en contra de la intromisión de sujetos foráneos al medio y se propone reconquistar un terreno que le ha sido arrebatado por un proceso de industrialización y urbanización en la selva. En este cuento notamos que los personajes que toman conciencia de su cruda situación en el mundo son precisamente los animales. Su disputa busca restablecer el orden, el equilibrio y la identidad de su hábitat: "Anaconda, en complicidad con los elementos nativos del trópico, meditó y planeó la 
reconquista del río" (304). Los animales de la selva tienen un plan de ataque estratégico que consiste, en primer lugar, en aprovechar la temporada de lluvias e inundaciones de la región para así lograr acercarse a las embarcaciones que navegan sobre el río. No obstante, el fenómeno climático se retrasa en llegar, indicando que la causa de esta anormalidad se debe al régimen nocivo al que la selva ha sido expuesta:

de lo que había sido cauce de umbríos arroyos solo quedaban piedras lisas y quemantes; y los esteros densísimos de agua negra y camalotes, hallábanse convertidos en paramos de arcilla surcada de rastros durísimos que encubría una red de filamentos deshilachados como estopa, y que era cuanto quedaba de la gran flora acuática (594).

El fragmento anterior ilustra cómo las nuevas mediaciones en este sector, entre ellas la introducción de maquinarias para la explotación y urbanización del territorio, han contaminado el ambiente. La severa contaminación del área ha afectado su conservación y ha provocado, también, una aguda época de sequía. Esta difícil situación hace que esta comunidad de animales evoque con nostalgia un tiempo pasado en el que el trayecto de la naturaleza seguía su curso habitual:

Pero ya no iba la boa a su río. Antes, hasta donde alcanzaba la memoria de sus antepasados, el río había sido suyo. Aguas, cachoerias, lobos, tormentas, todo le pertenecía [...] ahora no. Un hombre, primero, con su miserable ansia de ver, tocar y cortar había emergido tras el cabo de arena con su larga piragua. Luego otros hombres, con otros más, cada vez más frecuentes (594).

Esta reflexión plantea cómo la conducta humana es la única responsable por los desastres que afectan a la naturaleza. El hombre, en su deseo agresivo por descubrir, explotar y habitar territorios, no solo ha contaminado el ambiente, sino que también ha cercenado su curso vital, su propiedad y su ímpetu. Es por esto que, en el contexto narrativo de este cuento, el enemigo a vencer es el hombre. El ecosistema, por su parte, es la víctima principal del trato indiscriminado de la humanidad, por lo que tiene lugar el levantamiento del reino animal. Tanto la anaconda, líder de esta contienda, como los demás miembros de la fauna se organizan para ejecutar su cruzada. De hecho, "muy poco costó a Anaconda convencer a los animales. El hombre ha sido, es y será el más cruel enemigo de la selva" (595). 
En respuesta a esta crisis vivencial, Quiroga les otorga a los participantes locales de esta comunidad una agencia política. Al proporcionarles a estas víctimas la capacidad de denunciar y de esquematizar actos de rebelión, les posibilita ejercer una presión efectiva sobre los nuevos integrantes de la sociedad. Los animales son de hecho dotados de un intelecto lógico y discursivo que les autoriza a articular posturas coherentes de enfrentamiento a la cruda realidad. Es por esto que están conscientes de su situación en el mundo y son capaces de plantear proyectos que desafían la embestida moderna en el sector. En el cuento, la anaconda y los animales de la selva deben esperar el inicio de la temporada de lluvias, puesto que solo así aquellos hombres "no podrán llegar hasta aquí" (595). Una vez que empieza a llover torrencialmente, la anaconda se desplaza por las inundaciones para comprobar que el paso del hombre ha sido frenado y su acceso hacia la selva le ha sido truncado.

En ese trayecto, el animal se topa con una choza que ha sido arrastrada por las fuertes corrientes de agua. Sobre su techo yace un jornalero que agoniza por una herida mortal en su cuerpo. La anaconda, al percatarse de la presencia del herido, decide resguardarlo y acompañarlo en ese recorrido. Cuando las demás anacondas advierten esta situación, se disponen a atacar al hombre y rematarlo, pero el animal protector reacciona violentamente ante las demás serpientes: “¡no se pasa, he dicho! ¡Atrás! He tomado a ese hombre enfermo bajo mi protección. ¡Cuidado con la que se acerque!” (602). Para las anacondas, esta conducta es estimada como una traición: " $i$ te has vendido a los hombres...! ¡Iguana de cola larga!” (602). Anaconda, sin embargo, ignora las recriminaciones y permanece con el herido hasta que éste fallece. Mientras esto ocurre, la serpiente observa cómo logran aproximarse diversas embarcaciones: "grandes buques -los vencedores- ahumaban a lo lejos del cielo límpido y un vaporcito empenachado de blanco, curioseaba entre las islas rotas" (607). La aparición de estos "grandes buques vencedores" indica la irrupción exitosa del empuje urbano, que logra violentar el hábitat de estos animales. Para aquellos hombres, la presencia de la anaconda es, igualmente, amenazante, ya que se espantan al observar su gran tamaño: " $i Q u e ́$ monstruo! -Gritó otra voz-. ¡Y fijense! ¡Hay un rancho caído! Seguramente ha matado a su habitante - jo lo ha devorado vivo! Estos monstros no perdonan a nadie. Vamos a vengar al desgraciado con una buena bala" (607). De este modo, la anaconda muere a manos de estos sujetos que anulan su ciclo de vida.

Es interesante destacar aquí dos aspectos que son definitivos para la constitución del cuento. Por un lado, como ya hemos observado, la anaconda y la comunidad de animales de la selva emprenden una cruzada con el 
objetivo de defender su ecosistema y reconquistar el territorio del que han sido despojados. Por otro lado, la anaconda, líder de este grupo, se solidariza con un hombre moribundo tendido sobre el techo de su rancho, el cual ha sido arrojado por la corriente del río. Pese a que estos animales anuncian abiertamente que la actividad humana ha sido la responsable de la desgracia de la naturaleza, la anaconda se abstiene de asesinar al campesino. Por el contrario, lo protege, desafiando a las otras anacondas que sí intentaban asesinarlo. La anaconda, entonces, como partícipe de esta naturaleza, lucha por frenar la intromisión de los buques que transportan la impronta moderna y se resiste a romper el vínculo existente entre el ecosistema y el jornalero. La correspondencia entre el medio y el hombre rural está aún latente en la disposición de la anaconda. Pese a su muerte, su defensa y su enfrentamiento con las demás anacondas revelan su postura ética. El animal entiende su lugar en el mundo, está consciente de la contaminación del medio y asume que la conducta humana es la responsable de su declive. No obstante, comprende también que el hombre moribundo es una víctima más de la violencia ejercida sobre la selva. La muerte de ambos personajes indica el final de un tiempo histórico, mientras que los sujetos en los buques simbolizan la fundación de un nuevo pacto social.

En el cuento "La cámara oscura" (1920), Quiroga expone de manera mucho más efectiva en qué consisten los nuevos saberes y los novedosos artefactos culturales que impactaron la estabilidad de la selva misionera. En esta ocasión, el rioplatense incorpora una de sus grandes pasiones: la fotografía. Desde el sugerente título del cuento, Quiroga alude a la importancia que tiene la inserción de este instrumento óptico para el marco contextual. De hecho, el narrador informa tempranamente que el asunto fotográfico es el tema del relato. Su incorporación moviliza la estructura del cuento y le otorga más efectividad a su propósito. Todas las impresiones que tenemos de la condición de la selva y de la organización social de Misiones son presentadas a través de la voz narradora. En este caso, se trata de un fotógrafo moderno, un sujeto forastero que llega a Misiones a instalar su propio taller (no se precisa en el cuento qué tipo de taller es éste). Paralelamente, este personaje puede ser considerado como un alter ego de Quiroga. Su sensibilidad visual, ampliada por la actividad fotográfica, le permite exponer no solo el evidente rechazo que provoca su presencia en la comunidad misionera, sino también exhibir una imagen más precisa del estado actual de esta sociedad. Su participación dentro de esta colectividad informa sobre la inclusión de nuevos sujetos en el escenario de la selva. Simultáneamente, las descripciones que este forastero 
elabora indican que, así como él, existen otros extranjeros que han logrado internarse en este escenario.

En este contexto, el cuento se propone demostrar el desencuentro producido entre el influjo modernizante de la ciudad y los modos de vida campesina. De ahí que la voz que narra se concentre en detallar el ocaso de un campesino luego de su visita a la ciudad de Buenos Aires. Este personaje es Malaquías Sotelo, el juez de paz de la localidad, quien "era un indio de baja estatura y cuello muy corto" (648) y quien, además, portaba "dos ojillos hundidos que miraban con eterna desconfianza" (648). El juez de paz puede ser calificado como un sujeto aculturado que logra insertarse y ascender socialmente. Esta tendencia fue significativa para la obtención de su cargo jurisdiccional:

Había sido desde muchacho soldado de policía en la campana de Corrientes. La ola de desasosiego que como un viento norte sopla sobre el destino de los individuos en los países extremos, lo empujó a abandonar de golpe su oficio por el de portero del juzgado letrado de Posadas. Allí, sentado en el zaguán, aprendió solo a leer La nación y La prensa (649).

El fragmento anterior nos da señales del amplio desarrollo de los medios masivos de comunicación, entre los que se encuentran los periódicos $L a$ Nación ${ }^{5}$ y La Prensa ${ }^{6}$. Para el contexto narrativo, la referencia a estos medios no solo indica su acceso exitoso a la periferia, sino que expone, también, su función instrumental para la alfabetización de sujetos como el juez de paz. Su autoinstrucción es un mecanismo necesario para la adquisición de su ocupación municipal. Es, quizás, por esta razón que este personaje manifiesta una desconfianza por la presencia en su comunidad de nuevos

\footnotetext{
Diario argentino fundado por el expresidente de la República Argentina, Bartolomé Mitre, en 1870. Es uno de los periódicos con mayor trayectoria en este país y continúa manteniendo gran prestigio entre sus seguidores contemporáneos. La Nación es un diario que ha sido, históricamente, de tendencia conservadora y que ha servido a lo largo de los años como canal de comunicación de los ideales de la iglesia católica, de las fuerzas militares y de los sectores de producción agropecuaria del país.

Diario argentino fundado en 1869 por el periodista, político y diplomático José Camilo Paz. Al igual que La Nación, ha sido considerado como un diario de tendencia conservadora. Además de su inclinación política, este diario se destacó por ser uno de los grandes difusores del liberalismo económico en la Argentina. En la actualidad, el diario forma parte de una fusión de medios de comunicación organizados en la ciudad de Mar del Plata, Argentina, conocido como Multimedios la capital.
} 
sujetos que amenazan el estatus que con tanto empeño había alcanzado. Para los miembros de la sociedad misionera, y particularmente para el juez de paz, la coexistencia con los extranjeros provoca una constante tensión. El fotógrafo, en su capacidad perceptiva, se fija en los ojos de los residentes locales y en lo que su mirada le comunica. Asimismo, esta capacidad para interpretar la mirada de los residentes locales le sirve para comprender su conducta y su forma de relacionarse con el medio.

En este cuento, la impresión visual ocupa un lugar primordial para el acto descriptivo. La información que tenemos del juez de paz, es decir de Sotelo, está basada, exclusivamente, en lo que expresa su mirada. Por ejemplo, el fotógrafo insiste en que Sotelo tenía "ojillos hundidos" que "miraban con eterna desconfianza", además de señalar que "en el fondo, el hombre me quería poco o por lo menos desconfiaba de mí" (650). Simultáneamente, el forastero destaca en el juez de paz una postura ambivalente con relación con los "invasores" del sector. Si bien es cierto que Sotelo expresa un evidente rechazo, esto no es impedimento para que se case con Elena Pilsudski, una chica polaca recientemente llegada al sector de Misiones. Para el fotógrafo, Sotelo tuvo "buen ojo" (705) para escoger a su compañera de vida, lo que significa, también, una oportunidad de seguir medrando en esta sociedad. El narrador ejercita una tendencia descriptiva que se apoya en el carácter visual y en las imágenes fijadas por el ojo humano. Por supuesto, esto es posible por la correspondencia que el fotógrafo mantiene con su cámara oscura y las imágenes que el aparato fotográfico le permite descubrir. Todas las apreciaciones que este sujeto elabora del medio y de sus residentes están pensadas en función del ojo humano y lo que la mirada cautelosa de sus habitantes le provoca. Respaldado en su visualidad, el fotógrafo percibe no solo una tensión en Sotelo, sino también una crisis profunda al interior de la selva.

Es interesante notar cómo en este cuento el ímpetu de la ciudad moderna tiene secuelas desfavorables en los pobladores de esta zona de la selva misionera. El fotógrafo forastero cuenta que, luego del viaje de Sotelo a Buenos Aires, este último se contagió de una enfermedad extraña. Su encuentro con el núcleo urbano degenera al juez de paz, quien sufre de un virus que lo encamina a una muerte dolorosa. En su lecho de muerte, Sotelo es incapaz de pronunciar palabra alguna, por lo que le es imposible explicar el motivo de su contagio. La imagen que nos arroja el fotógrafo es una en la que Sotelo padece una descomposición de su cuerpo. En ese estado, "sus manos, saliendo a medias del puño de la camisa, descarnadas y con las uñas azules; los dedos lívidos y pegados que comenzaban a arquearse sobre las sábanas" (652). 
En este relato entran en juego factores históricos que permiten tratar el tema de la enfermedad y de la muerte del juez de paz como una consecuencia directa del impacto que produjo la sociedad moderna industrial sobre el sector de la frontera misionera. Los síntomas y la enfermedad funcionan como agentes que ocasionan la degradación de la condición humana. La enfermedad y la muerte de sus personajes son sugerentes del estado caótico en el que se encuentra la sociedad.

En "La cámara oscura" (1920), el fotógrafo introduce una imagen que aborda esta situación:

En el puerto nuevo de IVARAROMÍ se levanta un gran galpón nuevo que sirve de depósito de yerba, y se arruina un chalet deshabitado que en un tiempo fue almacén y casa de huéspedes. Ahora está vacío, sin que se halle en las piezas muy oscuras otra cosa que alguna guarnición mohosa de coche, y un aparato telefónico por el suelo. En una de estas piezas encontré al nuestro juez acostado vestido en un catre sin saco (706).

En este lugar conviven, de manera conflictiva, dos momentos históricos que se oponen de manera radical. Por un lado, se introduce el "gran galpón nuevo" que en la actualidad textual funciona como "depósito de yerba", "vacío", pero que en un tiempo pasado sirvió como "almacén y casa de huéspedes". Esta alusión da una idea de la degradación del tiempo histórico presente, cuyo futuro luce incierto y aterrador. Por otro lado, este lugar resguarda artefactos de la tecnología en desuso y ya descontextualizados, como el "aparato telefónico por el suelo" y "la guarnición mohosa de coche". Este escenario degradante hace que Sotelo no solo luzca desamparado e incapaz de generar un cambio, sino que también sugiere la inminente muerte del juez de paz. El forastero, en su función de fotógrafo moderno, guardará para la memoria colectiva los últimos momentos del juez:

Yo no lograba apartar de mis ojos al individuo dejando caer la mandíbula y fijando a perpetuidad la mirada en un costado del techo, para que no tuviera dudas de que no podía moverse más porque estaba muerto. Y he aquí que debía verlo de nuevo, reconsiderarlo, enfocarlo y revelarlo en mi cámara oscura (708).

Esta circunstancia es correlativa con el carácter autobiográfico del cuento. Quiroga escenifica a un personaje fotógrafo que tiene una reciprocidad tanto con su propio proyecto de vida como con su proyecto literario. El 
monte es pensado aquí como un lugar propicio para recuperar el equilibrio entre el hombre y la naturaleza que ya había sido desestabilizado por la preponderancia urbana moderna. No obstante, el escritor se da cuenta de que este medio rural ha sido intervenido por las regulaciones metropolitanas. Esto lo notamos, por ejemplo, en la inclusión de artefactos tecnológicos en desuso y la participación de nuevos ciudadanos en la convivencia de la comunidad misionera. La muerte de sus residentes locales y el malestar que manifiestan por la presencia de los extranjeros exponen un momento conflictivo que termina con la desaparición de una parte histórica y tradicional de la selva misionera. La condición del ámbito rural y la situación del campesinado indican que ésta es una coyuntura que afecta a toda una nación. A su vez, es significativa la presencia de la cámara fotográfica y la función que tiene la mirada en este cuento. A través de éstas, Quiroga nos da una impresión más precisa del estado decadente de la selva y el padecimiento de sus moradores.

En los cuentos de Quiroga aquí analizados, vemos que el autor le da un protagonismo especial al medio rural y a sus animales. Estos actores de la trama narrativa, junto a los pioneros moribundos, forman parte de una colectividad que se encuentra en franco descenso. Pese a la calamidad que experimentan los protagonistas del escenario misionero, éstos luchan arduamente por detener su penosa caída. El estado de esta naturaleza revela el porvenir de esta nación que se encuentra en pleno proceso de modernización. Quiroga documenta así estos acontecimientos históricos y los ficcionaliza, dejando constancia no solo de los efectos nocivos del ímpetu moderno, sino también de la resistencia que se efectúa desde las esferas tradicionales de la sociedad.

\section{BIBLIOGRAFÍA}

Arango, Manuel Antonio. "Sobre dos cuentos de Horacio Quiroga". THESAURUS, Boletín del Instituto Caro y Cuervo 1 (1982): 153-161.

Beauchamp, Juan José. "Subdesarrollo, ideología y visión del mundo en relatos de ambiente en Horacio Quiroga.” Revista de Estudios Hispánicos 6 (1979): 85-120.

Flores, Ángel. Aproximaciones a Horacio Quiroga. Caracas: Monte Ávila Editores, 1976.

Jitrik, Noé. "Soledad: Hurañía, desdén, timidez”. Aproximaciones a Horacio Quiroga. Ed. Ángel Flores. Caracas: Monte Ávila Editores, 1976. 93-118.

Morales, Leonidas. Figuras literarias, rupturas culturales: modernidad e identidades culturales tradicionales. Santiago: Pehuén Editores, 1993.

Paoli, Roberto. "El perfecto cuentista: Comentario a tres cuentos de Horacio Quiroga." Revista Iberoamericana 58 (1992): 959-969. 
Quiroga, Horacio “Hombre muerto". Jiménez, José Olivio. La prosa modernista hispanoamericana. Madrid: Alianza Editorial, 1998.

Los cuentos de Horacio Quiroga. Ed. Luís Benitez. Buenos Aires: Ediciones Díada S.R.L, 2008.

Rodríguez Monegal, Emir. "Horacio Quiroga. Vida y creación”. Narradores de esta América. Montevideo: Editorial Arca, 1992. 30-41.

Sarmiento, Domingo Faustino. Facundo. Buenos Aires: Emecé Editores, 1999.

Videla, Gloria. "Sobre «El hombre muerto» de Horacio Quiroga”. Explicación de textos literarios, Department of Foreign Languages, California State University (1982-1984): 11-18.

Zum Felde, Alberto. Critica de la literatura uruguaya. Ed. Maximino García. Montevideo: MCM XXI, 1921. 